\title{
Comparing the income-related inequity of tested prevalence and self-reported prevalence of hypertension in China
}

\author{
Min Su${ }^{1}$, Yafei $\mathrm{Si}^{1}$, Zhongliang Zhou ${ }^{{ }^{*}}$, Chi Shen ${ }^{1}$, Wanyue Dong ${ }^{2}$, Xiaojing Fan ${ }^{2}$, Xiao Wang ${ }^{3}$ and Xiaolin Wei ${ }^{4^{*}}$
}

\begin{abstract}
Background: Hypertension has become a global health challenge given its high prevalence and but low awareness and detection. Whether the actual prevalence of hypertension has been estimated is important, especially for the poor. This study aimed to measure tested prevalence and self-reported prevalence of hypertension and compare the inequity between them in China.

Methods: Data were derived from China Health and Nutrition Survey (CHNS) conducted in 2011. By using the multistage, stratified, random sampling method, 12,168 respondents aged 18 or older were identified for analysis. Both tested prevalence (systolic blood pressure $\geq 140 \mathrm{mmHg}$ or/and diastolic blood pressure $\geq$ $90 \mathrm{mmHg}$ or /and current use any of antihypertensive medication) and self-reported prevalence (ever diagnosed with hypertension by a doctor) were used to measure the prevalence of hypertension. The concentration index was employed to measure the extent of inequality in tested prevalence and self-reported prevalence. A decomposition method, based on a Probit model, was used to analyze income-related horizontal inequity of tested prevalence and self-reported prevalence.
\end{abstract}

Results: The tested prevalence and self-reported prevalence of total respondents were $28.8 \%$ [95\% Cl (28.0\%, 29.6\%)] and $15.7 \%[95 \% \mathrm{Cl}(15.0 \%, 16.3 \%)]$, and $26.4 \%$ [95\% Cl $(25.1 \%, 27.6 \%)]$ and $19.0 \%[95 \% \mathrm{Cl}(17.9 \%, 20.1 \%)]$ in urban areas, and $30.3 \%$ [95\% Cl $(29.3 \%, 31.4 \%)]$ and $13.5 \%$ [95\% Cl (12.7\%, 14.3\%)] in rural areas. The horizontal inequity indexes of mean tested prevalence and self-reported prevalence were -0.0494 and 0.1203 of total respondents, -0.0736 and 0 . 0748 in urban area, and -0.0177 and 0.0466 in rural area respectively, indicating pro-poor inequity in tested prevalence and pro-rich inequity in self-reported prevalence of hypertension. Economic status, education attainment and age were key factors of the pro-poor inequity in tested prevalence. Economic status, area and age were key factors to explain the poor-rich inequity in self-reported prevalence.

Conclusions: This study revealed self-reported prevalence of hypertension was much lower than tested prevalence in China, while a larger gap between self-reported and tested prevalence was found in rural areas. Our study suggested social strategies aiming at narrowing economic gap and regional disparities, reducing educational inequity, and facilitating health conditions of the elderly should be implemented. Finally, awareness raising campaigns to test hypertension in rural area need be strengthened by health education programs and improving the access to public health service, especially for those who do not engage with regular health checkups.

Keywords: China, Tested prevalence, Self-reported prevalence, Hypertension, Income-related health inequality, Decomposition, Horizontal inequity

\footnotetext{
* Correspondence: zzliang1981@163.com; xiaolin.wei@utoronto.ca

${ }^{1}$ School of Public Policy and Administration, Xi'an Jiaotong University, Xi'an,

China

${ }^{4}$ Dalla Lana School of Public Health, University of Toronto, Toronto, Canada

Full list of author information is available at the end of the article
}

(c) The Author(s). 2018 Open Access This article is distributed under the terms of the Creative Commons Attribution 4.0 International License (http://creativecommons.org/licenses/by/4.0/), which permits unrestricted use, distribution, and

reproduction in any medium, provided you give appropriate credit to the original author(s) and the source, provide a link to the Creative Commons license, and indicate if changes were made. The Creative Commons Public Domain Dedication waiver (http://creativecommons.org/publicdomain/zero/1.0/) applies to the data made available in this article, unless otherwise stated. 


\section{Background}

Hypertension has long been regarded as a crucial global health challenge given its high prevalence and leading risks for cardiovascular disease but low awareness and detection [1-3]. The past four decades have experienced a globally increasing number of population suffering from hypertension, which increased from 594 million in 1975 to 1.13 billion in 2015 world-wide [4, 5]. Residents living with hypertension may experience heavier burden of disease. As the GBD 2015 reported [5], hypertension has become the second risk factor accounting for 211.8 million disability-adjusted life-years (DALYs). Furthermore, residents with hypertension may be at a higher risk of incurring catastrophic health care expenditure especially for the poor [2]. Regarding the serious consequences, the awareness, detection, diagnosis and control of hypertension are significantly important for reducing the risks of hypertension. However, hypertension can be asymptomatic, and many patients living with hypertension may have not seen a doctor $[6,7]$. Thus, it has become a crucial global health challenge for the awareness, detection and diagnosis of hypertension. By the end of 2011, there were approximately $28.6 \%$ of adults had hypertension in China and only $37.6 \%$ of them were diagnosed by a doctor [8]. Therefore, strategies aiming at improving the awareness, detection and diagnosis of hypertension and relieving the disease burden of residents with hypertension are essential.

Chinese government has carried out a wide range of health reforms to protect residents against hypertension since 2009, among which the basic free national public health program towards the achievement of universal health coverage is one of the most important policy interventions. The basic free public health services have been provided to the residents to establish a dynamic health record, screening those with hypertension or other chronic diseases for further monitoring, treating and controlling. In addition, annual free health check is available for each elderly people aged 65 or older, which also includes the screening of hypertension [9]. By the end of 2011, the proportion of people established health record in primary healthcare facilities accounted for over $50 \%$, and more than 39 million aged people obtained health check free of charge [9-11].

Another intervention, the basic health insurance schemes, is also effective to release more demands of preventive care by the financial support for health care [12]. Thus, the residents with hypertension or other chronic diseases covered by more generous schemes are more likely to be diagnosed. There are three basic health insurance schemes in China: Urban Employee Basic Medical Insurance (UEBMI) for urban residents who work in formal sectors, Urban Resident Basic Medical Insurance (URBMI) for the rest urban residents without formal jobs or unemployment, and the New Rural Cooperative Medical Scheme (NRCMS) in rural areas [10]. The UEBMI, NRCMS and URBMI have been piloted in 1998, 2003 and 2007 respectively. In addition, there were approximately 252.3 million people enrolled in the UEBMI and 220.7 million people enrolled in the URBMI by the end of 2011, accounting for 36.5 and $31.9 \%$ of the total urban residents respectively. There were 0.8 billion people (accounting for $97.5 \%$ of the total rural residents) enrolled in the NRCMS by the end of 2011 [11]. However, the administration, pooling levels, and benefit packages are quite different across different schemes. For example, NRCMS involves a Household Account for critical outpatient care, such as stage III hypertension, whilst UEBMI sets up an Individual Account for more generous coverage for outpatient care [9].

Numerous studies have revealed that inequalities in socioeconomic status are associated with inequalities in health services and health outcomes. For example, higher economic and education level, good employment status, developed region, and having health insurance were all regarded as important factors of higher health service utilization and better health outcomes [12-15]. Furthermore, an increasing literature has shown lower economic and education level, absence of health insurance, and having chronic diseases (e.g. hypertension and diabetes) were associated with higher risk of inequality in catastrophic healthcare expenditure $[3,16]$. Although China has made great progress in the management of hypertension and other chronic diseases, a key question is whether the actual prevalence of hypertension has been estimated, especially in the groups of lower socioeconomic status. Using different methods to measure the prevalence of hypertension and compare the income-related inequality between them can provide insights into the detection, awareness and diagnosis of hypertension. Prior research indicated that the self-reported measurements may result in an underestimation of the prevalence of hypertension primarily because many people are unaware of their conditions. However, most current studies only used tested measures or self-reported measures to reveal the prevalence of hypertension [16-20]. Therefore, measuring the inequality of hypertension prevalence is one of the most prevalent concerns for the entire health system. Given the strong disparity between tested prevalence and self-reported prevalence, the inequality of hypertension based on self-reported data may be less accurate than medical measurements. However, little evidence was available to measure and compare the income-related inequality between tested prevalence and self-reported prevalence of hypertension based on a large-scale survey of national households in China. Hence this study aimed to fill the gap by measuring tested prevalence and 
self-reported prevalence of hypertension and comparing the income-related inequality between them, and further decomposing the income-related inequality into the contributing factors, based on a nationally representative sample aged 18 years or older in 2011. This study will provide evidence-based strategies on reducing the income-related inequality of both tested and self-reported hypertension prevalence in China and other developing countries.

\section{Methods}

\section{Ethics}

The ethics approval was obtained by the review board from the University of North Carolina at Chapel Hill, National Institute for Nutrition and Food Safety, China Center for Disease Control and Prevention and China-Japan Friendship Hospital. Informed consent was obtained, and data were anonymized for the analysis.

\section{Data}

Data were derived from the China Health and Nutrition Survey (CHNS) conducted in 2011. The CHNS, an international project, aimed to collect a nationally representative sample of Chinese residents to support the health and nutrition related research. The CHNS has been conducted every 2-4 years since 1989 [21, 22]. By using multistage, stratified, random sampling method, 9 primary sampling units of provinces/autonomous cities, 288 secondary units of communities and 5884 households were interviewed. Since this study focused on the respondents aged 18 years and older, 12,168 respondents were identified in the final sample for further analysis after data cleaning. Among those, urban respondents were 4791 (39.4\%) and rural respondents were 7377 (60.6\%). More details of the CHNS were available here (http://www.cpc.unc.edu/projects/chinak).

\section{Dependent variables}

A subject was defined as having hypertension with two methods: tested prevalence and self-reported prevalence. For tested prevalence, mercury sphygmomanometers were used to measure each respondent's systolic blood pressure (SBP) and diastolic blood pressure (DBP) three times after setting for $10 \mathrm{~min}$. Then the mean SBP and DBP values were calculated. A subject was defined as having hypertension if he/she had an average $\mathrm{SBP} \geq$ $140 \mathrm{mmHg}$ or/and DBP $\geq 90 \mathrm{mmHg}$ or current use of any anti-hypertensive medication, following the WHO guidelines $[6,22,23]$. For self-reported prevalence, the interviewees were asked: "Have you ever been diagnosed with hypertension by a doctor?" A subject was defined as having hypertension if he/she answered "Yes".

\section{Independent variables}

With reference to previous research [23-26], seven categories of factors, which may be related to the prevalence of hypertension were used in this study. Firstly, demographic characteristics and health statuses, including seven variables: gender, age, height, weight, educational achievement, marital status and self-reported diabetes status. BMI was calculated as weight divided by the square of the height $\left(\mathrm{kg} / \mathrm{m}^{2}\right)$. BMI were categorized as underweight $\left(\mathrm{BMI}<18.5 \mathrm{~kg} / \mathrm{m}^{2}\right)$, normal weight $\left(18.5 \leq \mathrm{BMI}<25.0 \quad \mathrm{~kg} / \mathrm{m}^{2}\right), \quad$ overweight $\quad(25.0 \leq \mathrm{BMI}<$ $\left.30.0 \mathrm{~kg} / \mathrm{m}^{2}\right)$ and obese $\left(\mathrm{BMI} \geq 30.0 \mathrm{~kg} / \mathrm{m}^{2}\right)$ according to WHO classifications [3, 27]. The interviewees were asked: "Have you ever been diagnosed with diabetes by a doctor?" A subject was defined as having diabetes if he/ she answered "Yes". Secondly, utilization of preventative health service, including a dummy variable (e.g. whether receive preventative health service during the last 4 weeks). Thirdly, basic health insurance, including a dummy variable: having basic health insurance or not. Fourthly, economic status was measured by annual individual income, and grouped into five quintiles. Furthermore, geographic characteristic (area), consisting of 9 provinces including Liaoning, Heilongjiang, Jiangsu, Shandong, Henan, Hubei, Hunan, Guangxi and Guizhou, which were grouped into three areas (e.g. East, Middle and West of China). Finally, risk factors for hypertension, including two variables: smoking and drinking. Specially, respondents who ever consumed any form of tobacco were defined as smokers; respondents who consumed beer or any other alcoholic beverage last year were defined as drinkers. With reference to previous research, only variables passed the multicollinearity test were included, with none of the variables having a VIF greater than 4 [28].

\section{Health inequity Concentration index}

Concentration index was applied to quantify the income-related inequality in both tested prevalence and self-reported prevalence of hypertension [29, 30]. Concentration index ranges from -1 to 1 , and 0 represents no income-related inequality $[31,32]$. The positive score of concentration index indicates pro-rich inequality in prevalence, and the negative score of concentration index indicates pro-poor inequality. The Eq.1 was used to calculate the concentration index:

$$
\mathrm{C}=\frac{2}{\mu} \operatorname{cov}(y, r)
$$

Where $\mathrm{C}$ represents concentration index, $y$ represents the prevalence of hypertension, $\mu$ represents the mean of 
the prevalence of hypertension, and $\gamma$ represents the fractional rank of income distribution [33].

\section{Decomposition methods of concentration index}

The income-related inequality of tested prevalence and self-reported prevalence of hypertension could be explained by decomposing concentration index into the contributing factors based on a Probit model, using Eq.2 and Eq.3 [34]. As the Probit model is a nonlinear model, the linear approximation to the nonlinear model was conducted by estimating the partial effects evaluated at the covariate means.

$$
y_{i}=\alpha+\sum_{j} \beta_{j}^{m} x_{j i}+\sum_{k} r_{k}^{n} z_{k i}+\varepsilon_{i}
$$

where $y_{i}$ represents the prevalence of hypertension; $\mathrm{X}$ represents the need factors of hypertension prevalence. Need factors are the unavoidable determinants of hypertension prevalence. As Wagstaff and Van Doorslaer suggested, gender and age are commonly used to reflect need factors of health $[15,16,35]$; $\mathrm{z}$ represents the nonneed factors of hypertension prevalence. Non-need factors are the avoidable determinants of hypertension prevalence, including annual individual income, educational states, marital states, BMI, diabetes, smoke, drink, area, basic health insurance and utilization of preventative health service, following the literature [15, 16, 35]; $\beta_{j}^{m}$ and $r_{k}^{n}$ are marginal effects of each variable; $\varepsilon_{i}$ stands for the error. The concentration index $\mathrm{C}$ could also be written as:

$$
\mathrm{C}=\sum_{j}\left(\beta_{j}^{m \overline{x_{j}}} /{ }_{\mu}\right) C_{j}+\mathrm{G} C_{\varepsilon} /_{\mu}
$$

Where $\mu$ is the mean of the prevalence of hypertension, $C_{j}$ are the concentration index for $x_{j}$ and $\overline{x_{j}}$ are the means of $x_{j}$. The contributions of independent variables are indicated by the first item on the right side of Eq.3 to the inequality of prevalence indicators, the last term is the generalized concentration index of $\varepsilon$. From Eq.3, we can see that the overall inequality can be divided into two parts: explained part calculated by the first term and unexplained part calculated by the last term [33].

\section{Horizontal inequity index}

The horizontal inequity index of health, which indicates the inequality of health for the people who have the same unavoidable health conditions, was measured by deducting the contributions of need factors from the concentration index of health $[35,36]$. In this study, the horizontal inequity index of hypertension prevalence was obtained by removing the contributions of need factors (gender and age) from the overall concentration index of hypertension prevalence. A positive (negative) horizontal inequity index indicated the pro-rich (pro-poor) inequity. All analyses were performed in Stata 13.0.

\section{Results}

\section{Descriptive analysis}

In 2011, among the whole respondents $(12,168)$, the annual individual income was RMB 17,012 (urban: RMB 21,567; rural: RMB 14,060). More than half of the total respondents tended to be females and the percentages of female and male respondents in both urban and rural areas were roughly equal. Majority of respondents had normal weight, had an education level at secondary school, have been diagnosed with diabetes by a physician, never smoke and drink, had basic health insurance, and received preventative health service in the last 4 weeks. More details can be found in Table 1 .

\section{Mean SBP, mean DBP, tested prevalence and self- reported prevalence}

The mean SBP of total respondents was $124.4 \pm$ $17.7 \mathrm{mmHg}$ (urban: $124.1 \pm 17.0 \mathrm{mmHg}$; rural: $124.6 \pm$ $17.2 \mathrm{mmHg}$ ) and the mean DBP was $79.2 \pm 10.7 \mathrm{mmHg}$ (urban: $78.8 \pm 9.9 \mathrm{mmHg}$; rural: $79.5 \pm 11.2 \mathrm{mmHg}$ ). The tested prevalence and self-reported prevalence of total respondents were $28.8 \%$ [95\% CI $(28.0 \%, 29.6 \%)]$ and $15.7 \%$ [95\% CI $(15.0 \%, 16.3 \%)]$, and $26.4 \%$ [95\% CI $(25.1 \%, 27.6 \%)]$ and $19.0 \%$ [95\% CI $(17.9 \%, 20.1 \%)]$ in urban areas, and 30.3\% [95\% CI $(29.3 \%, 31.4 \%)]$ and $13.5 \%$ [95\% CI $(12.7 \%, 14.3 \%)]$ in rural areas (Table 2). It was notable significant differences between tested prevalence and self-reported prevalence of total respondents were observed (both urban and rural areas) at the level of $\alpha=0.05$. It was also worth noting the gap between tested prevalence and self-reported prevalence of total population, urban residents and rural respondents was $13.1 \%, 7.4 \%$ and $16.8 \%$ respectively.

Table 2 also presents tested prevalence and self-reported prevalence of hypertension in different economic quantiles. In terms of tested prevalence, the poorest had the highest probability of hypertension $[33.1 \%, 95 \% \mathrm{CI}$ $(31.2 \%, 35.0 \%)]$, while the richest had the lowest probability of hypertension [25.2\%, 95\% CI $(23.5 \%, 27.0 \%)]$, and the trend was consistent in both urban and rural areas. However, the self-reported prevalence indicated an increase from the poorest $[13.4 \%, 95 \%$ CI $(12.1 \%$, $14.8 \%)]$ to the richest $[19.9 \%, 95 \%$ CI $(18.4 \%, 21.5 \%)]$, and the trend was also consistent in both urban and rural areas.

\section{Concentration index and decomposition Concentration index}

The income-related inequalities of tested prevalence for the whole population, urban and rural areas were -0.0544 
Table 1 Description of independent variables in 2011

\begin{tabular}{|c|c|c|c|c|}
\hline Variables & Description of variables & $\begin{array}{l}\text { Total } \\
\text { N (\%) }\end{array}$ & $\begin{array}{l}\text { Urban } \\
\text { N (\%) }\end{array}$ & $\begin{array}{l}\text { Rural } \\
\text { N (\%) }\end{array}$ \\
\hline \multicolumn{5}{|l|}{ Gender } \\
\hline Male $^{a}$ & & $5757(47.31)$ & $2272(47.42)$ & $3485(47.24)$ \\
\hline Female & Male $=0$, female $=1$ & $6411(52.69)$ & 2519(52.58) & $3892(52.76)$ \\
\hline \multicolumn{5}{|l|}{ Age group } \\
\hline $18-44^{\mathrm{a}}$ & & $4346(35.72)$ & 1658(34.61) & $2688(36.44)$ \\
\hline $45-59$ & $45-59=1$, else $=0$ & 4038(33.19) & 1566(32.69) & 2472(33.51) \\
\hline$>60$ & 60 and above $=1$, else $=0$ & 3784(31.10) & 1567(32.71) & $2217(30.05)$ \\
\hline \multicolumn{5}{|l|}{ BMI } \\
\hline Underweight $^{a}$ & $\mathrm{BMI}<18.5 \mathrm{~kg} / \mathrm{m}^{2}$ & $621(5.18)$ & $222(4.69)$ & 399(5.49) \\
\hline Normal weight & $18.5 \leq \mathrm{BMl}<25.0 \mathrm{~kg} / \mathrm{m}^{2}=1$, else $=0$ & $5864(48.88)$ & $2272(48.04)$ & $3592(49.42)$ \\
\hline Overweight & $25.0 \leq \mathrm{BMl}<30.0 \mathrm{~kg} / \mathrm{m}^{2}=1$, else $=0$ & $3756(31.31)$ & $1529(32.33)$ & $2227(30.64)$ \\
\hline Obese & $\mathrm{BMI} \geq 30.0 \mathrm{~kg} / \mathrm{m}^{2}=1$, else $=0$ & 1756(14.64) & $706(14.93)$ & $1050(14.45)$ \\
\hline \multicolumn{5}{|l|}{ Diabetes } \\
\hline $\mathrm{No}^{\mathrm{a}}$ & & $11,673(95.93)$ & 4496(96.84) & 7177(97.27) \\
\hline Yes & Have been diagnosed with diabetes by a doctor $=1$, else $=0$ & 482(3.96) & 285(5.95) & 197(2.67) \\
\hline \multicolumn{5}{|l|}{ Education } \\
\hline Illiterate or Primary ${ }^{\mathrm{a}}$ & & 4338(35.70) & 1063(22.23) & $3275(44.44)$ \\
\hline Secondary & Secondary $=1$, else $=0$ & $6326(52.07)$ & 2699(56.45) & $3627(49.22)$ \\
\hline College or above & College degree or above $=1$, else $=0$ & $1486(12.23)$ & 1019(21.31) & $467(6.34)$ \\
\hline \multicolumn{5}{|l|}{ Marital status } \\
\hline Single $e^{a}$ & & $641(5.36)$ & $339(7.21)$ & $302(4.16)$ \\
\hline Marriage & Marriage $=1$, else $=0$ & $10,108(84.53)$ & $3876(82.42)$ & $6232(85.90)$ \\
\hline Others & Others $=1$, else $=0$ & 1209(10.11) & 488(10.38) & $721(9.94)$ \\
\hline \multicolumn{5}{|l|}{ Smoke } \\
\hline $\mathrm{No}^{\mathrm{a}}$ & Never smoke & $8463(69.55)$ & $3386(70.67)$ & $5077(68.82)$ \\
\hline Yes & Smoke $=1$, else $=0$ & $3701(30.42)$ & 1403(29.28) & 2298(31.15) \\
\hline \multicolumn{5}{|l|}{ Drink } \\
\hline $\mathrm{No}^{\mathrm{a}}$ & Never drink & $8048(66.14)$ & $3011(62.85)$ & $5037(68.28)$ \\
\hline Yes & Drink beer or alcohol last year $=1$, else $=0$ & $4118(33.84)$ & 1778(37.11) & $2340(31.72)$ \\
\hline \multicolumn{5}{|l|}{ Area } \\
\hline East of China ${ }^{a}$ & Living in the east of China & $5188(42.64)$ & 2359(49.24) & 2829(38.35) \\
\hline Middle of China & Living in the middle of China $=1$, else $=0$ & $5058(41.57)$ & 1644(34.31) & $3414(46.28)$ \\
\hline West of China & Living in the west of China $=1$, else $=0$ & 1922(15.80) & $788(16.45)$ & 1134(15.37) \\
\hline \multicolumn{5}{|l|}{ Basic health insurance } \\
\hline $\mathrm{No}^{\mathrm{a}}$ & Absence basic health insurance & $414(3.40)$ & 205(4.28) & $209(2.83)$ \\
\hline Yes & Having basic health insurance $=1$, else $=0$ & $11,751(96.60)$ & 4583(95.72) & 7168(97.17) \\
\hline \multicolumn{5}{|c|}{ Preventative health service } \\
\hline $\mathrm{No}^{\mathrm{a}}$ & & $901(7.40)$ & $448(9.35)$ & $453(6.14)$ \\
\hline Yes & Receiving preventative health service in the last four weeks $=1$, else $=0$ & $11,255(92.50)$ & 4339(90.57) & 6916(93.75) \\
\hline \multicolumn{5}{|l|}{ Economic status } \\
\hline Quintile1 (poorest ${ }^{\mathrm{a}}$ ) & $20 \%$ low income individuals & 2429(19.96) & $957(19.97)$ & 1474(20.01) \\
\hline Quintile2 (poorer) & $20 \%$ lower income individuals $=1$, else $=0$ & 2431(19.98) & 954(19.91) & 1477(20.05) \\
\hline Quintile3 (middle) & $20 \%$ middle-income individuals $=1$, else $=0$ & 2424(19.92) & $955(19.93)$ & $1470(19.96)$ \\
\hline
\end{tabular}


Table 1 Description of independent variables in 2011 (Continued)

\begin{tabular}{lllll}
\hline Variables & Description of variables & Total & Urban & $\begin{array}{c}\text { Rural } \\
\text { N (\%) }\end{array}$ \\
\hline Quintile4 (richer) & 20\% higher income individuals = 1, else = & $2429(19.96)$ & $954(19.91)$ & $1473(20.00)$ \\
Quintile5 (richest) & $20 \%$ high income individuals = 1, else = & $2426(19.94)$ & $953(19.89)$ & $1472(19.98)$ \\
Observations & & 12,168 & 4791 & 7377 \\
\hline
\end{tabular}

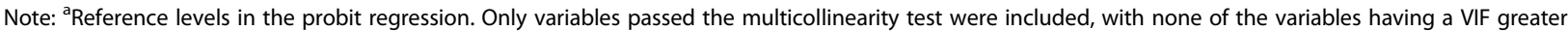
than 4

[95\% CI $(-0.0705,-0.0383)],-0.0626[95 \%$ CI $(-0.0899$, $-0.0353)]$, and -0.0367 [95\% CI $(-0.0567,-0.0167)]$ respectively, which meant that the poor had a higher prevalence of hypertension based on the tested measurement. However, the income-related inequalities of self-reported prevalence of hypertension for the whole population, urban and rural areas were 0.0888 [95\% CI (0.0551, $0.0225)], 0.0436$ [95\% CI $(0.0103,0.0769)]$, and 0.0893 [95\% CI $(0.0656,0.1131)]$ respectively, which meant that the rich had a higher self-reported prevalence of hypertension.

\section{Decomposition of inequality in tested prevalence and self- reported prevalence}

The decomposition of concentration index of the tested prevalence and self-reported prevalence of hypertension are presented in Tables 3 and 4 respectively. The estimated partial effects of related factors of inequality in tested prevalence and self-reported prevalence of hypertension were calculated based on Probit model. Contribution to the inequality and the proportion of contribution in the overall concentration index are also reported. A negative marginal effect of annual individual income, taking the tested prevalence of total respondents for example, indicated a higher income level was significantly associated with lower tested prevalence, whilst a positive marginal effect of age for instance, suggested the tested prevalence increased along the ageing population.

After decomposing the concentration index, the income-related inequality was decomposed into the contribution of different variables. And a positive (negative) contribution represented the variable raised (reduced) the inequality [34]. It indicated that majority of the inequality of tested hypertension prevalence of total respondents were attributable to economic status (56.0\%), education attainment (46.1\%) and age (14.2\%) by defining the contribution as proportions of each variable. It also indicated that majority of the inequality of tested hypertension prevalence in urban areas were attributable to economic status (59.7\%), education attainment (38.6\%) and BMI (19.8\%). And the income-related in the tested prevalence of hypertension in rural areas were mainly explained by age (60.3\%), economic status $(50.6 \%)$ and education attainment (37.5\%). In terms of self-reported prevalence, the majority of the inequality of self-reported hypertension prevalence of total respondents were attributable to economic status (56.3\%), area (29.9\%) and age $(-16.2 \%)$. In the urban areas, most of the inequality of self-reported hypertension prevalence were attributable to economic status (48.2\%), area (38.0\%) and education attainment $(-22.0 \%)$. And the income-related in the self-reported prevalence of hypertension in the rural areas were mainly explained by economic status (91.7\%), marital status (-45.5\%), and area $(43.4 \%)$.

\section{Horizontal inequity index}

The horizontal inequity index of tested prevalence and self-reported prevalence of hypertension are presented in Table 5. The horizontal inequity index of tested prevalence and self-reported prevalence of hypertension were -0.0494 and 0.1203 of total respondents, -0.0736

Table 2 Tested prevalence and self-reported prevalence of hypertension in different economic quantiles, 2011 (\%)

\begin{tabular}{|c|c|c|c|c|c|c|}
\hline & \multicolumn{2}{|l|}{ Total } & \multicolumn{2}{|l|}{ Urban } & \multicolumn{2}{|l|}{ Rural } \\
\hline & $\begin{array}{l}\text { Tested } \\
\text { prevalence }\end{array}$ & $\begin{array}{l}\text { Self-reported } \\
\text { prevalence }\end{array}$ & $\begin{array}{l}\text { Tested } \\
\text { prevalence }\end{array}$ & $\begin{array}{l}\text { Self-reported } \\
\text { prevalence }\end{array}$ & $\begin{array}{l}\text { Tested } \\
\text { prevalence }\end{array}$ & $\begin{array}{l}\text { Self-reported } \\
\text { prevalence }\end{array}$ \\
\hline Quintile 1 (poorest) & $33.10(31.23,34.97)$ & $13.42(12.06,14.78)$ & $31.77(28.81,34.72)$ & $15.88(13.56,18.20)$ & $34.12(31.70,36.55)$ & $13.30(11.56,15.03)$ \\
\hline Quintile 2 (poorer) & $29.41(27.60,31.22)$ & $13.04(11.70,14.38)$ & $26.31(23.51,29.11)$ & $15.20(12.92,17.48)$ & $30.87(28.51,33.23)$ & $11.65(10.00,13.28)$ \\
\hline Quintile 3 (middle) & $28.18(26.38,29.97)$ & $14.07(12.68,15.45)$ & $26.39(23.59,29.19)$ & $18.01(15.57,20.45)$ & $30.14(27.79,32.48)$ & $13.33(11.59,15.07)$ \\
\hline Quintile 4 (richer) & $27.79(26.01,29.57)$ & $17.83(16.30,19.35)$ & $26.62(22.60,28.13)$ & $22.96(20.28,25.63)$ & $28.45(26.14,30.75)$ & $13.17(11.44,14.49)$ \\
\hline Quintile 5 (richest) & $25.23(23.50,26.96)$ & $19.95(18.36,21.50)$ & $21.39(19.30,24.56)$ & $22.98(20.30,25.66)$ & $27.85(25.65,30.15)$ & $16.30(14.16,17.91)$ \\
\hline Total & $28.76(27.96,27.67)$ & $15.68(15.03,16.33)$ & $26.38(25.13,27.63)$ & $19.01(17.90,20.13)$ & $30.30(29.26,31.36)$ & $13.51(12.73,14.30)$ \\
\hline
\end{tabular}


Table 3 Partial effect and contribution to concentration index(Tested prevalence)

\begin{tabular}{|c|c|c|c|c|c|c|c|c|c|}
\hline \multirow[t]{2}{*}{ Variables } & \multicolumn{3}{|l|}{ Total } & \multicolumn{3}{|l|}{ Urban } & \multicolumn{3}{|l|}{ Rural } \\
\hline & $\mathrm{dy} / \mathrm{dx}$ & Con & $\%$ & $d y / d x$ & Con & $\%$ & $d y / d x$ & Con & $\%$ \\
\hline Annual individual income & & & 55.98 & & & 59.71 & & & 50.56 \\
\hline Quintile2 (poorer) & -0.0189 & 0.005 & -9.69 & -0.0327 & 0.010 & -15.80 & -0.0112 & 0.002 & -6.37 \\
\hline Quintile3 (middle) & -0.0210 & 0.000 & 0.01 & -0.0320 & 0.000 & 0.03 & -0.0104 & -0.001 & 3.75 \\
\hline Quintile4 (richer) & $-0.0283^{*}$ & -0.008 & 14.47 & $-0.0420^{*}$ & -0.013 & 20.39 & -0.0113 & -0.004 & 9.97 \\
\hline Quintile5 (richest) & $-0.0501^{* * *}$ & -0.028 & 51.19 & $-0.0569^{* *}$ & -0.034 & 55.09 & -0.0429 & -0.016 & 43.21 \\
\hline Female & $0.0756^{* * *}$ & 0.003 & -5.37 & $0.0837^{* * *}$ & 0.002 & -3.68 & $0.0644^{* * *}$ & 0.003 & -8.06 \\
\hline Age(years) & & & 14.16 & & & -12.89 & & & 60.26 \\
\hline $45-59$ & $0.1590^{* * *}$ & 0.007 & -13.56 & $0.1155^{* * *}$ & -0.001 & 2.21 & $0.1891^{* * *}$ & 0.016 & -43.62 \\
\hline$>60$ & $0.3002^{* * *}$ & -0.015 & 27.72 & $0.2727^{* * *}$ & 0.010 & -15.10 & $0.3293^{* * *}$ & -0.038 & 103.88 \\
\hline BMI & & & -10.06 & & & 19.80 & & & -34.83 \\
\hline Normal weight & $0.1642^{* * *}$ & -0.003 & 4.84 & $0.1583^{* *}$ & 0.004 & -6.29 & $0.1706^{* * *}$ & -0.005 & 12.86 \\
\hline Overweight & $0.3121^{* * *}$ & 0.019 & -34.64 & $0.2938^{* * *}$ & 0.011 & -17.15 & $0.3273^{* * *}$ & 0.021 & -57.99 \\
\hline Obese & $0.5764^{* * *}$ & -0.011 & 19.74 & $0.5675^{* * *}$ & -0.027 & 43.24 & $0.5833^{* * *}$ & -0.004 & 10.30 \\
\hline Diabetes & $0.0609^{* * *}$ & 0.001 & -2.54 & $0.0620^{*}$ & 0.001 & -2.12 & $0.0779^{*}$ & 0.001 & -2.09 \\
\hline Education & & & 46.41 & & & 38.62 & & & 37.53 \\
\hline Secondary & $-0.0571^{* * *}$ & -0.005 & 8.71 & $-0.0476^{* * *}$ & 0.002 & -3.04 & $-0.0454^{* *}$ & -0.005 & 14.65 \\
\hline College or above & $-0.0992^{* * *}$ & -0.020 & 37.70 & $-0.0850^{* * *}$ & -0.026 & 41.66 & $-0.0837^{* *}$ & -0.008 & 22.92 \\
\hline Marital status & & & 4.08 & & & 2.33 & & & 10.28 \\
\hline Marriage & -0.0083 & 0.000 & 0.48 & 0.0163 & 0.000 & -0.68 & -0.0333 & -0.002 & 4.89 \\
\hline Others & 0.0392 & -0.002 & 3.60 & 0.0447 & -0.002 & 3.01 & 0.0331 & -0.002 & 5.39 \\
\hline Smoke & 0.0049 & 0.000 & 0.09 & -0.0100 & 0.000 & -0.77 & 0.0144 & 0.000 & -0.70 \\
\hline Drink & $0.0267^{*}$ & 0.002 & -3.33 & 0.0233 & 0.000 & -0.70 & $0.0317^{*}$ & 0.002 & -6.54 \\
\hline Area & & & -0.73 & & & 6.29 & & & -7.39 \\
\hline Middle of China & 0.0096 & -0.002 & 4.13 & $0.0321^{*}$ & -0.007 & 11.73 & -0.0049 & 0.001 & -2.60 \\
\hline West of China & $-0.0281^{*}$ & 0.003 & -4.86 & -0.0209 & 0.003 & -5.44 & -0.0281 & 0.002 & -4.79 \\
\hline Basic insurance & 0.0359 & -0.002 & 3.15 & 0.0317 & -0.002 & 2.71 & 0.0444 & -0.002 & 4.93 \\
\hline Preventative health service & $0.0288^{*}$ & 0.001 & -2.48 & $0.0258^{*}$ & 0.002 & -2.27 & 0.0393 & 0.001 & -3.34 \\
\hline
\end{tabular}

Note: $d y / d x$ the partial effect in Probit regression model, Con the contribution to inequality; \%, the share of contribution index. ${ }^{*} P<0.05$; ${ }^{* *} P<0.01 ;{ }^{* * *} P<0.001$

and 0.0748 in urban area, and -0.0177 and 0.0466 in rural area respectively.

\section{Discussions}

\section{Self-reported prevalence and tested prevalence of}

\section{hypertension}

We investigated the prevalence of hypertension as well as its income-related inequality in China by using the data from the China Health and Nutrition Survey (CHNS) conducted in 2011. The results of this study revealed that self-reported prevalence of hypertension was much lower than tested prevalence in China. And similar trends were observed in both rural and urban areas. However, a larger gap between tested prevalence and self-reported prevalence was found in rural areas (16.8\%). It's worth noting that the gap between these two measurements in rural areas may be larger than
$16.8 \%$ because we only focused on the current use of any anti-hypertensive medication. However, previous studies have revealed that $20 \%$ of patients who ever taken drugs stopped drugs at least a month [36]. Compared with urban residents, there are many challenges in having proper anti-hypertensive drugs in rural areas because of the limited qualification of physicians, heavy reliance on traditional therapies and the cost of such drugs [36-38]. It has been demonstrated that nearly $50 \%$ of hypertension patients were not receiving any anti-hypertensive medication in a national survey and only $24.6 \%$ in Yunnan province and $46.34 \%$ in Zhejiang province [37, 39-41].

Our results were comparable to those found in a prior study that used the same data in 2011 to measure the prevalence and awareness in Chinese adults. In that study, approximately $28.6 \%$ of Chinese adults had 
Table 4 Partial effect and contribution to concentration index (Self-reported prevalence)

\begin{tabular}{|c|c|c|c|c|c|c|c|c|c|}
\hline \multirow[t]{2}{*}{ Variables } & \multicolumn{3}{|l|}{ Total } & \multicolumn{3}{|l|}{ Urban } & \multicolumn{3}{|l|}{ Rural } \\
\hline & $d y / d x$ & Con & $\%$ & $d y / d x$ & Con & $\%$ & $d y / d x$ & Con & $\%$ \\
\hline Annual individual income & & & 56.27 & & & 48.23 & & & 91.73 \\
\hline Quintile2 (poorer) & 0.0069 & -0.004 & -3.95 & -0.0141 & 0.006 & 6.65 & $0.0211^{*}$ & -0.010 & -22.75 \\
\hline Quintile3 (middle) & 0.0111 & 0.000 & 0.01 & -0.0136 & 0.000 & -0.01 & $0.0216^{*}$ & 0.006 & 14.68 \\
\hline Quintile4 (richer) & $0.0243^{*}$ & 0.012 & 13.91 & 0.0166 & 0.007 & 7.87 & $0.0248^{*}$ & 0.018 & 41.21 \\
\hline Quintile5 (richest) & $0.0406^{* * *}$ & 0.041 & 46.30 & 0.0356 & 0.030 & 33.72 & $0.0308^{*}$ & 0.026 & 58.59 \\
\hline Female & 0.0020 & 0.000 & 0.15 & 0.0104 & 0.000 & 0.45 & -0.0019 & 0.000 & -0.45 \\
\hline Age(years) & & & -16.19 & & & 15.16 & & & -7.48 \\
\hline $45-59$ & $0.1742^{* * *}$ & 0.015 & 16.60 & $0.1988^{* * *}$ & -0.003 & -3.72 & $0.1562^{* * *}$ & 0.0300 & 67.98 \\
\hline$>60$ & $0.3180^{* * *}$ & -0.046 & -32.79 & $0.3487^{* * *}$ & 0.017 & 18.88 & $0.2851^{* * *}$ & -0.033 & -75.46 \\
\hline BMI & & & 7.27 & & & -4.61 & & & 26.59 \\
\hline Normal weight & $0.0582^{* * *}$ & -0.002 & -1.91 & $0.1222^{* * *}$ & 0.004 & 4.75 & $0.0298^{*}$ & -0.002 & -4.24 \\
\hline Overweight & $0.1499^{* * *}$ & 0.017 & 18.58 & $0.2271^{* * *}$ & 0.012 & 12.97 & $0.1147^{* * *}$ & 0.017 & 38.31 \\
\hline Obese & $0.2456^{* * *}$ & -0.008 & -9.40 & $0.0998^{* * *}$ & -0.020 & -22.33 & $0.2245^{* * *}$ & -0.003 & -7.48 \\
\hline Diabetes & $0.1461^{* * *}$ & 0.006 & 6.81 & $0.1834^{* * *}$ & 0.005 & 6.13 & $0.1030^{* * *}$ & 0.0023 & 5.21 \\
\hline Education & & & -13.34 & & & -21.97 & & & -23.52 \\
\hline Secondary & $-0.0173^{*}$ & -0.003 & -2.94 & -0.0238 & 0.001 & 1.48 & $-0.0239^{* *}$ & -0.006 & -14.58 \\
\hline College or above & $-0.0245^{*}$ & -0.009 & -10.40 & $-0.0489^{* *}$ & -0.021 & -23.45 & -0.0173 & -0.004 & -8.94 \\
\hline Marital status & & & -12.84 & & & -7.08 & & & -45.50 \\
\hline Marriage & $0.0774^{* * *}$ & 0.005 & 5.10 & $0.0750^{*}$ & 0.003 & 3.05 & $0.0834^{* *}$ & 0.010 & 23.13 \\
\hline Others & $0.1748^{* * *}$ & -0.016 & -17.94 & $0.1539^{* *}$ & -0.009 & -10.13 & $0.2235^{* *}$ & -0.030 & -68.63 \\
\hline Smoke & -0.0012 & 0.000 & 0.02 & -0.0010 & 0.000 & 0.07 & 0.0007 & 0.000 & 0.07 \\
\hline Drink & -0.0022 & 0.000 & -0.31 & -0.0116 & 0.000 & -0.34 & 0.0034 & 0.000 & 1.32 \\
\hline Area & & & 29.93 & & & 37.99 & & & 43.42 \\
\hline Middle of China & $-0.0395^{* * *}$ & 0.017 & 18.94 & $-0.0523^{* * *}$ & 0.017 & 18.71 & $-0.0284^{* * *}$ & 0.013 & 28.67 \\
\hline West of China & $-0.0569^{* * *}$ & 0.010 & 10.99 & $-0.0759^{* * *}$ & 0.018 & 19.28 & $-0.0460^{* * *}$ & 0.006 & 14.75 \\
\hline Basic insurance & -0.0019 & 0.000 & 0.19 & 0.0052 & 0.000 & -0.43 & -0.0123 & 0.001 & 2.58 \\
\hline Preventative health service & $0.0936^{* * *}$ & 0.008 & 8.99 & $0.0927^{* * *}$ & 0.007 & 7.97 & $0.0938^{* * *}$ & 0.007 & 15.05 \\
\hline
\end{tabular}

Note: $d y / d x$ the partial effect in Probit regression model, Con the contribution to inequality; \%, the share of contribution index. ${ }^{*} \mathrm{P}<0.05 ;{ }^{* * *} \mathrm{P}<0.01$; ${ }^{* * * *} \mathrm{P}<0.001$

Table 5 Contributions and horizontal inequity of tested prevalence and self-reported prevalence of hypertension

\begin{tabular}{|c|c|c|c|c|c|c|c|c|c|c|c|c|}
\hline & \multicolumn{4}{|l|}{ Total } & \multicolumn{4}{|l|}{ Urban } & \multicolumn{4}{|l|}{ Rural } \\
\hline & \multicolumn{2}{|l|}{ Tested } & \multirow{2}{*}{$\begin{array}{l}\text { Self-reported } \\
\text { Con }\end{array}$} & \multirow[b]{2}{*}{$\%$} & \multicolumn{2}{|l|}{ Tested } & \multicolumn{2}{|c|}{ Self-reported } & \multicolumn{2}{|l|}{ Tested } & \multicolumn{2}{|c|}{ Self-reported } \\
\hline & Con & $\%$ & & & Con & $\%$ & Con & $\%$ & Con & $\%$ & Con & $\%$ \\
\hline \multicolumn{13}{|l|}{ Need factors } \\
\hline Age-gender & -0.0050 & 8.79 & -0.0310 & -16.04 & 0.0110 & -16.57 & 0.0140 & 15.61 & -0.0190 & 52.20 & -0.0030 & -7.93 \\
\hline \multicolumn{13}{|l|}{ Non-need factors } \\
\hline Economic level & -0.0310 & 55.98 & 0.0490 & 56.27 & -0.0370 & 59.71 & 0.0430 & 48.23 & -0.0190 & 50.56 & 0.0400 & 91.97 \\
\hline Other factors & -0.0190 & 33.92 & 0.0025 & 19.90 & -0.0410 & 63.89 & 0.0170 & 11.60 & 0.000 & -2.15 & 0.0113 & 25.22 \\
\hline Residual & 0.0004 & 1.31 & 0.0688 & 39.87 & 0.0044 & -7.03 & 0.0148 & 24.56 & 0.0013 & -4.91 & -0.0047 & -9.26 \\
\hline $\mathrm{Cl}$ & -0.0544 & 100 & 0.0893 & 100 & -0.0626 & 100 & 0.0888 & 100 & -0.0367 & 100 & 0.0436 & 100 \\
\hline $\mathrm{HI}$ & -0.0494 & & 0.1203 & & -0.0736 & & 0.0748 & & -0.0177 & & 0.0466 & \\
\hline
\end{tabular}


hypertension in 2011 [26]. Our results indicated a similar tested prevalence $(28.8 \%$ for the total respondents, $26.4 \%$ in urban areas and $30.3 \%$ in rural areas) and an extremely low self-reported prevalence of hypertension in China $(15.7 \%$ for the total respondents, $19.0 \%$ in urban areas and $13.5 \%$ in rural areas), which showed a low-level diagnosis and awareness of hypertension. It was also consistent with other international studies that there existed large gap between self-reported prevalence and tested prevalence in other low-income and middle-income countries (e.g. nearly $31 \%$ in Ghana, $10 \%$ in India, $40 \%$ in South Africa, and 16\% in Mexico) [42].

\section{Poor-rich inequity in self-reported prevalence and poor- poor inequity in tested prevalence}

The negative concentration index in tested prevalence of hypertension revealed that the poor tended to have higher tested prevalence than the rich, while the positive concentration index in self-reported prevalence of hypertension revealed that the rich people tended to have higher self-reported prevalence of hypertension than the poor, which was consistent with other low-income and middle-income countries. For example, the concentration index of self-reported and tested prevalence of hypertension was 0.02 and -0.07 in Russia, 0.14 and -0.02 in South Africa, and 0.19 and 0.03 in India, respectively. [42].

By removing the contributions of need factors (gender and age) from the overall concentration index, we compared the horizontal inequity index of tested prevalence and self-reported prevalence. The negative horizontal inequity index of tested prevalence revealed that controlling the unavoidable characteristics of respondents living with hypertension, there still existed the pro-poor inequity of prevalence. However, the positive horizontal inequity index of self-reported prevalence revealed that there existed the pro-rich inequity of prevalence.

The significant difference between tested prevalence and self-reported prevalence of hypertension, and inequity between them should be noted. If self-reports were used to measure the prevalence of hypertension, we may get unreal or extremely opposite conclusion that the rich tended to have high prevalence of hypertension. One potential factor could be responsible for this phenomenon. In 2011, an estimated less than 50\% of adults aged 65 or older obtained health check although annual free health check is available for each elderly people aged 65 or older. And another public intervention was established that outpatients aged 35 or older are required to measure blood pressure at first when they seek outpatient care. However, the low self-reported prevalence indicated that there was a big problem in the access and utilization of preventative health service or other public health programs, which resulted in a big detection, awareness and management of major non-communicable diseases $[9,23]$. In other words, the self-reported prevalence was more likely to reflect the accessibility of healthcare and public health programs other than the actual prevalence. Therefore, tested measurements were more reliable to estimate the prevalence of hypertension. Given hypertension is the determining risk factor for cardiovascular diseases and cerebrovascular diseases, our results highlighted the need to take positive measures to improve basic public health service system to screen those with hypertension or other chronic diseases for further monitoring, treating and controlling, including perfecting free health check program, establishing a dynamic health record and improving the quality of family doctors to ensure the longitudinal use of primary healthcare and preventative health service over time, and optimizing health education program and interventions. Based on the tested prevalence, this study indicated that the poor tended to have high prevalence of hypertension, thus further policy interventions aimed at improving the detection, awareness and management of hypertension and other chronic diseases should be taken to address the remaining pro-poor inequity.

\section{Decomposition of inequality in tested prevalence and self-reported prevalence}

Results from the decomposition suggested that economic status, education attainment and age were the key factors of the pro-poor inequality in tested prevalence. Take the total respondents for example, the total contributions of economic status and education attainment were $102.4 \%$ with negative association with tested prevalence and negative positive contribution, highlighting that the poorer and/or less educated individuals were more likely to have hypertension. One potential reason to explain this was that the richer or more educated respondents may have more knowledge and better health awareness about addressing risk factors of hypertension, such as unhealthy diet, harmful use of alcohol and lack of physical activity [25]. Age was the third largest factor with positive association with tested prevalence, highlighting that the older people have higher prevalence of hypertension. In terms of the self-reported prevalence, the total contributions of economic status and area were $86.2 \%$ with positive association with self-reported prevalence and positive contribution, highlighting that the richer and/or individuals who live in the eastern of China were more likely to have higher self-reported of hypertension. One potential reason to explain this was that the richer or individuals from eastern China (eastern China is the most developed part of China with higher per capita income and more advanced health system) could benefit more from health system and public health programs, owning to the higher economic level, better accessibility of healthcare and chronic disease 
management system. Age was the third largest factor with positive association with self-reported prevalence, highlighting that the older people have higher self-reported prevalence of hypertension. Not surprisingly, elderly people were more likely to have unfavorable health outcomes and thus more utilization of preventative health service or other public health programs. Finally, the results from decomposing of income-related inequality suggested it was necessary to consider the contributions of key determinants when formulating health policy interventions, allocating health resources and relieving health inequity. It is crucial to facilitate the health conditions of the aged population and narrow economic, educational and geographical gaps between the rich and the poor in both rural and urban residents. Our research highlighted several recommendations that might be helpful to narrow the healthcare service and health outcome gaps. First, more attention should be paid to combine health policy with all other major policies, especially with the poverty reduction policies (Health Assistance Program for Poverty Alleviation) $[43,44]$. Specifically, the health burdens of the poverty-stricken population should be alleviated by improving health insurance level. Furthermore, a triage system to the poor population with chronic diseases should be strengthened by establishing a dynamically electric health file and a health card. Adopting the mechanism of providing diagnosis and treatment before payment for the poor in cities or provinces where conditions permit would improve accessibility to critical healthcare [44, 45]. Second, more attention should be paid to the uneven geographic distribution in healthcare resources between urban and rural areas. Density of healthcare resources is significantly important for improving population health $[46,47]$. Equitable geographic distribution of healthcare resources is proven to be associated with equities in health outcomes [48]. The distribution of health resources was highly spatially clustered in China [48-51]. For example, the number of licensed doctors per 1000 registered population was 3.5 in urban areas in 2014, which was 2.3 times of rural areas [51]. The number of beds per 1000 people was 6.9 in urban areas, and 3.1 in rural areas [50]. To reduce the uneven geographic distribution in healthcare resources between urban and rural areas, the health funding levels, sources and mechanisms should be adjusted and optimized, with an aim of reducing the urban and rural gap [48].

\section{Strengths and limitations}

To sum up, our study has two key strengths. The first one is the large sample that is nationally representative, implying the conclusion from this study could be generalizable for the entire China. Apart from this, this is the first study to compare the inequity between tested prevalence and self-reported prevalence of hypertension and decompose into its contributing factors to explain health inequality based on a large-scale national household survey in China. This study will provide recommendations with an evidence-based approach for reducing the income-related inequality of hypertension prevalence and diagnosis in China and other developing countries. Two main limitations should also be noted in this study. Firstly, owing to the cross-sectional data, only correlation other than causality was investigated. Secondly, because of the data availability, we could not include all the unobservable variables. For example, dietary intake, work-related physical activity and comorbidity such as cardiovascular disease was not discussed in our study. The omission of these factors could lead to biased estimation of the inequality of hypertension prevalence.

\section{Conclusions}

This study revealed self-reported prevalence of hypertension was much lower than tested prevalence in China, while a larger gap between self-reported and tested prevalence was found in rural areas. Furthermore, there existed pro-poor inequity in tested prevalence and pro-rich inequity in self-reported prevalence of hypertension. Our studies suggested social strategies aiming at narrowing economic gap and regional disparities, reducing educational inequity, and facilitating health conditions of the elderly should be implemented. Finally, awareness raising campaigns to test hypertension in rural area need be strengthened by health education programs and improving the access to public health service, especially for those who do not engage with regular health checkups.

\section{Abbreviations}

Cl: Concentration Index; DBP: Diastolic blood pressure; HI: Horizontal inequity index; SBP: systolic blood pressure

\section{Funding}

This study was funded by the Research Program of China Medical Board (15227), Shaanxi Soft Science (2015KRM117), Shaanxi Social Science Foundation (2017S024), Shaanxi provincial youth star of science and technology and the National Program for Support of Top-notch Young Professionals. The authors would like to acknowledge the financial support of China Scholarship Council (CSC). The funding bodies had no role in the design of the study or collection, analysis, and interpretation of data, and they did not contribute to the writing of the manuscript.

\section{Availability of data and materials}

This data was drawn from the Data were derived from the China Health and Nutrition Survey (CHNS) conducted in 2011. They are opened to everyone. Researchers who want to use these data can visit http://www.cpc.unc.edu/ projects/china.

\section{Authors' contributions}

MS participated in the study design, data analysis and interpretation, and was the primary person responsible for drafting the manuscript. YS contributed to study design and revision. ZZ conceived of the study design and participated in 
revision. XF and CS contributed to data analysis and revision. WD, XW and XW participated in revision. All authors read and approved the final manuscript.

\section{Ethics approval and consent to participate}

The ethics approval was obtained by the review board from the University of North Carolina at Chapel Hill, National Institute for Nutrition and Food Safety, China Center for Disease Control and Prevention and China-Japan Friendship Hospital. Informed consent was obtained, and the data were anonymized for the analysis.

\section{Competing interests}

The authors declare that they have no competing interests.

\section{Publisher's Note}

Springer Nature remains neutral with regard to jurisdictional claims in published maps and institutional affiliations.

\section{Author details}

${ }^{1}$ School of Public Policy and Administration, Xi'an Jiaotong University, Xi'an, China. ${ }^{2}$ School of Public Health, Xi'an Jiaotong University, Xi'an, China. ${ }^{3}$ International Business School Suzhou, Xi'an Jiaotong-Liverpool University, Suzhou, China. ${ }^{4}$ Dalla Lana School of Public Health, University of Toronto, Toronto, Canada.

\section{Received: 29 December 2017 Accepted: 4 June 2018}

Published online: 15 June 2018

\section{References}

1. Bromfield S, Muntner P. High blood pressure: the leading global burden of disease risk factor and the need for worldwide prevention programs. Curr Hypertens Rep. 2013;15(3):134-6. https://doi.org/10.1007/s11906-013-0340-9.

2. NCD Risk Factor Collaboration. Worldwide trends in diabetes since 1980: a pooled analysis of 751 population-based studies with 4.4 million participants. Lancet. 2016;387:1513-30. https://doi.org/10.1016/S01406736(16)00618-8.

3. Xu Y, Gao J, Zhou Z, Xue Q, Yang J, Luo H, Li Y, Lai S, Chen G. Measurement and explanation of socioeconomic inequality in catastrophic health care expenditure: evidence from the rural areas of Shaanxi Province. BMC Health Serv Res. 2015;15:256. https://doi.org/10.1186/s12913-015-0892-2.

4. World Health Organization. Prevention of cardiovascular disease[M]. World Health Organization, 2007.

5. GBD 2015 Risk Factors Collaborators. Global, regional, and nationa comparative risk assessment of 79 behavioral, environmental and occupational, and metabolic risks or clusters of risks, 1990-2015: a systematic analysis for the Global Burden of Disease Study 2015. Lancet. 2016;388:1659-724. https://doi.org/10.1016/S0140-6736(16)31679-8.

6. Ong KL, Cheung BMY, Man YB, et al. Prevalence, awareness, treatment, and control of hypertension among United States adults 1999-2004. Hypertension. 2007;49(1):69-75. https://doi.org/10.1161/01.HYP.0000252676. 46043.18

7. Yusufali A, Khatib R, Islam S, et al. Lbos 03-01 prevalence, awareness, treatment, and control of hypertension in the Middle East: results from the prospective urban rural epidemiology (pure) study. J Hypertens. 2016;34: e551. https://doi.org/10.1097/01.hjh.0000501507.52547.6e

8. Guo J, Zhu Y, Chen $Y$, Hu Y, Tang X, Zhang B. The dynamics of hypertension prevalence, awareness, treatment, control and associated factors in Chinese adults: results from CHNS1991-2011. J Hypertens. 2015;33(8):1688-96. https://doi.org/10.1097/HJH.0000000000000594.

9. Feng X. Undiagnosed and uncontrolled chronic conditions in China: Could social health insurance consolidation make a change? Med Care Res Rev. 2017; https://doi.org/10.1177/1077558717690303.

10. Meng Q, Fang H, Liu X, Yuan B, Xu J. Consolidating the social health insurance schemes in China: towards an equitable and efficient health system. Lancet. 2015;386(10002):1484-92. https://doi.org/10.1016/S01406736(15)00342-6.

11. CNBS (China National Bureau of Statistics). 2012. Statistical bulletin of national economy and social development of the year 2011. http://www. stats.gov.cn.

12. Devaux M. Income-related inequalities and inequities in health care services utilization in 18 selected OECD countries. Eur J Health Econ. 2015:16(1):2133. https://doi.org/10.1007/s10198-013-0546-4.
13. Macinko J, Lima-Costa M F. Horizontal equity in health care utilization in Brazil, 1998-2008. Int J Equity Health, 2012, 11(1): 33. https://doi.org/10. 1186/s12939-014-0101-7.

14. Zhu D, Guo N, Wang J, et al. Socioeconomic inequalities of outpatient and inpatient service utilization in China: personal and regional perspectives. Int J Equity Health. 2017;16(1):210. https://doi.org/10.1186/s12939-017-0706-8.

15. Zhou Z, Fang Y, Zhou Z, et al. Assessing income-related health inequality and horizontal inequity in China. Soc Indic Res. 2017;132(1):241-56. https:// doi.org/10.1007/s11205-015-1221-1.

16. Si Y, Zhou Z, Su M, et al. Catastrophic healthcare expenditure and its inequality for households with hypertension: evidence from the rural areas of Shaanxi Province in China[J]. Int J Equity Health. 2017;16(1):27. https://doi. org/10.1186/s12939-016-0506-6.

17. Guo X, Zheng L, Zhang X, Zou L, Li J, Sun Z, Hu J, Sun Y. The prevalence and heterogeneity of prehypertension: a meta-analysis and meta-regression of published literature worldwide. Cardiovascular Journal of Africa. 2012 23(1):44-79. http:/hdl.handle.net/10520/EJC23567.

18. Tesfaye B, Haile D, Lake B, Belachew T, Tesfaye T, Abera H. Uncontrolled hypertension and associated factors among adult hypertensive patients on follow-up at Jimma University teaching and specialized hospital: cross-sectional study. Research Reports in Clinical Cardiology. 2016;8:21-9.

19. Kuate D, Mbanya J, Tardif J, Ekundayo O, Perreault S, Potvin L, Cote R, Kengne AP, Choukem SP, Assah F, et al. Diagnosis, prevalence, awareness, treatment, prevention, and control of hypertension in Cameroon: protocol for a systematic review and meta-analysis of clinic-based and communitybased studies. JMIR research protocols. 2017;6(5):e102. https://doi.org/10. 2196/resprot.7807.

20. Nduka C, Stranges S, Sarki A, Kimani P, Uthman O. Evidence of increased blood pressure and hypertension risk among people living with HIV on antiretroviral therapy: a systematic review with meta-analysis. J Hum Hypertens. 2016:30(6):355-62. https://doi.org/10.1038/jhh.2015.97.

21. Jones-Smith JC, Popkin BM. Understanding community context and adult health changes in China: development of an urbanicity scale. Soc Sci Med. 2010;71:1436-46. https://doi.org/10.1016/j.socscimed.2010.07.027.

22. Zhang B, Zhai FY, Du SF, Popkin BM. The China Health and Nutrition Survey, 1989-2011. Obes Rev. 2014; 15 (Suppl 1):2-7. DOl: https://doi.org/10.1111/ obr.12119

23. Ning M, Zhang Q, Yang M. Comparison of self-reported and biomedical data on hypertension and diabetes: findings from the China Health and Retirement Longitudinal Study (CHARLS). BMJ Open. 2016;6:e009836. https://doi.org/10.1136/bmjopen-2015-009836

24. World Health Organization. Global status report on noncommunicable diseases 2010[M]. Geneva: World Health Organization, 2011.

25. World Health Organization. A global brief on hypertension: silent killer, global public health crisis: World Health Day 2013. 2013.

26. Reynolds K, Gu D, Muntner P, et al. Geographic variations in the prevalence, awareness, treatment and control of hypertension in China. J Hypertens. 2003:21(7):1273-81. https://doi.org/10.1097/00004872-200307000-00014.

27. Obesity: Preventing and Managing the Global Epidemic. Report of a WHO consultation on Obesity. Geneva: World Health Organization; 2001.

28. Asiimwe JB, Ndugga P, Mushomi J, et al. Factors associated with modern contraceptive use among young and older women in Uganda; a comparative analysis. BMC Public Health. 2014;14(1):926. https://doi.org/10. 1186/1471-2458-14-926.

29. Kakwani N, Wagstaff A, VanDoorslaer E. Socioeconomic inequalities in health. Measurement, computation, and statistical inference. J Econ. 1997; 77(1):87-103. https://doi.org/10.1016/S0304-4076(96)01807-6.

30. Zhou Z, Zhou Z, Gao J, Yang X, Yan J, Xue Q, Chen G. The effect of urban basic medical insurance on health service utilisation in Shaanxi Province, China: a comparison of two schemes. PLoS One. 2014;9(4):e94909. https:// doi.org/10.1371/journal.pone.0094909.

31. Wagstaff $A$. The bounds of the concentration index when the variable of interest is binary, with an application to immunization inequality. Health Econ. 2005;14:429-32. https://doi.org/10.1002/hec.953.

32. Collins E, Klein R. Equity and the NHS: self-reported morbidity, access, and primary care. BMJ. 1980;281(6248):1111-5. https://doi.org/10.1136/bmj.281. 6248.1111.

33. Wagstaff A, Van Doorslaer E, Paci P. Equity in the finance and delivery of health care: some tentative cross-country comparisons. Oxf Rev Econ Policy. 1989;5(1):89-112. http://www.jstor.org/stable/23606200. 
34. Wagstaff A, van Doorslaer E, Watanabe N. On decomposing the causes of health sector inequalities with an application to malnutrition inequalities in Vietnam. J Econometrics. 2003;112:207-23. https://doi.org/10.1016/S03044076(02)00161-6.

35. Su M, Zhou Z, Si Y, et al. Comparing the effects of China's three basic health insurance schemes on the equity of health-related quality of life: using the method of coarsened exact matching[]]. Health Qual Life Outcomes. 2018;16(1):41. https://doi.org/10.1186/s12955-018-0868-0.

36. Wei X, Zou G, Yin J, et al. Characteristics of high risk people with cardiovascular disease in Chinese rural areas: clinical indictors, disease patterns and drug treatment. PLoS One. 2013;8(1):e54169. https://doi.org/10. 1371/journal.pone.0124484

37. Zou G, Zhang Z, Walley J, et al. Use of medications and lifestyles of hypertensive patients with high risk of cardiovascular disease in rural China. PLoS One. 2015:10(5):e0124484. https://doi.org/10.1371/journal.pone.0124484.

38. Wei X, Walley JD, Zhang Z, et al. Implementation of a comprehensive intervention for patients at high risk of cardiovascular disease in rural China: a pragmatic cluster randomized controlled trial. PLoS One. 2017;12(8): e0183169. https://doi.org/10.1371/journal.pone.0183169.

39. Feng XL, Pang M, Beard J. Health system strengthening and hypertension awareness, treatment and control: data from the China Health and Retirement Longitudinal Study. Bull World Health Organ. 2014;92(1):29 https://doi.org/10.2471/BLT.13.124495.

40. Zhang J, Huang Q, Yu M, et al. Prevalence, awareness, medication, control, and risk factors associated with hypertension in Bai ethnic group in rural China: the Yunnan Minority Eye Study. PLoS One. 2013;8(8):e70886. https://doi.org/10.1371/journal.pone.0070886.

41. Wang $H$, Zhang $X$, Zhang J, et al. Factors associated with prevalence, awareness, treatment and control of hypertension among adults in southern China: a community-based, cross-sectional survey. PLoS One. 2013; 8(5):e62469. https://doi.org/10.1371/journal.pone.0062469.

42. Vellakkal S, Millett C, Basu S, et al. Are estimates of socioeconomic inequalities in chronic disease artefactually narrowed by self-reported measures of prevalence in low-income and middle-income countries? Findings from the WHO-SAGE survey. J Epidemiol Community Health. 2015; 69:218-25. https://doi.org/10.1136/jech-2014-204621.

43. Tan X, Zhang Y, Shao H. Healthy China 2030, a breakthrough for improving health. Glob Health Promot. 2018; https://doi.org/10.1177/ 1757975917743533.

44. National Health and Family Planning Commission of the PRC. Introduction of Implementing the Health and Medical Assistance Program for Poverty Alleviation. 2016. http://www.china.com.cn/zhibo/zhuanti/ch-xinwen/201606/21/content_38712035.htm

45. The State Council Information Office of the People's Republic of China. China's Progress in Poverty Reduction and Human Rights. 2016. http://english.gov.cn/policies/latest_releases/2016/10/17/content_ 281475468533275.htm

46. Anand S, Bärnighausen T. Human resources and health outcomes: crosscountry econometric study. Lancet. 2004;364(9445):1603-9. https://doi.org/ 10.1016/S0140-6736(04)17313-3.

47. Chen L, Evans T, Anand S, et al. Human resources for health: overcoming the crisis. Lancet. 2004;364(9449):1984-90. https://doi.org/10.1016/S01406736(04) 17482-5.

48. Pan J, Shallcross D. Geographic distribution of hospital beds throughout China: a county-level econometric analysis. Int J Equity Health. 2016;15(1): 179. https://doi.org/10.1186/s12939-016-0467-9.

49. Li D, Zhou Z, Si Y, et al. Unequal distribution of health human resource in mainland China: what are the determinants from a comprehensive perspective? Int J Equity Health. 2018;17(1):29. https://doi.org/10.1186/ s12939-018-0742-z.

50. World Health Organization. People's Republic of China health system review. 2015.

51. Gao Y, Zhou H, Singh NS, et al. Progress and challenges in maternal health in western China: a countdown to 2015 national case study. Lancet Glob Health. 2017:5(5):e523-36. https://doi.org/10.1016/\$2214-109X(17)30100-6.

\section{Ready to submit your research? Choose BMC and benefit from:}

- fast, convenient online submission

- thorough peer review by experienced researchers in your field

- rapid publication on acceptance

- support for research data, including large and complex data types

- gold Open Access which fosters wider collaboration and increased citations

- maximum visibility for your research: over $100 \mathrm{M}$ website views per year

At BMC, research is always in progress.

Learn more biomedcentral.com/submissions 